\title{
Julie Barbour
}

\section{Jespersen Cycles on Malekula}

DOI 10.1515/lingty-2015-0013

Received April 13, 2015; revised October 5, 2015

\begin{abstract}
In the indigenous languages of Malekula Island, members of Oceanic, diverse standard negation strategies have been identified, including double negation, simple preverbal negators, and simple postverbal negators. Individual languages may display more than one strategy. In this article, evidence from Malekula is considered for the typological hypothesis known as the Jespersen Cycle(s). Six standard negation strategies are described in detail and illustrated using data from a sample of Malekula languages. Here, the Jespersen Cycle hypothesis is employed to understand diversity in the synchronic patterning of standard negation in a comparative analysis of the sample: the diverse standard negation strategies found both language-internally and comparatively can be understood as iterations of the Jespersen Cycle(s).
\end{abstract}

Keywords: diachrony, Jespersen Cycle, Malekula, morphology, negation, Oceanic, syntax, word order

\section{Introduction}

\subsection{The languages of Malekula}

In this study, an account of negation is presented in a sub-set of the languages of Malekula Island in the nation of Vanuatu. Data for 16 languages are referred to, including six detailed case studies. The island of Malekula and its numerous small off-shore islands belong to the province of Malampa (Malekula-AmbrymPaama). The 2009 census records 36,727 people as residing in Malampa Province, with 27,825 being residents of Malekula and its small islands (Vanuatu National Statistics Office 2009: 13). This population is linguistically very diverse, with Lynch \& Crowley $(2001:$ 68, 85) identifying more than thirty languages as being spoken on the island.

Julie Barbour, School of Arts, The University of Waikato, Gate 1 Knighton Road, Private Bag 3105, Hamilton 3240, New Zealand, E-mail: jbarbour@waikato.ac.nz 
By the late twentieth century, the languages of Malekula were still largely undescribed, with just four reasonably substantial publications of linguistic material being available. These were Capell \& Layard's (1980) sketch and text collection of the Atchin variety of the Northeast Malekula language, Charpentier's (1979) French grammar of the Port Sandwich language, Crowley's (1998) sketch of the moribund Nāti language, and Fox's (1979) grammar of V'ënen Taut/Big Nambas. The situation today is much improved, with several language documentation projects, predominantly carried out by student researchers, having reached completion.

The Malekula languages belong to the Oceanic language family (Lynch et al. 2002: 4), which is a branch of the Austronesian language family (see, e.g., Ross et al. 2011: 7). More specifically, the languages are thought to belong to a North Central Vanuatu grouping (Clark 2009). Lynch (2014) has provided a recent subgrouping model of Malekula, where he divides the better known languages of Malekula into two main linkages. These linkages roughly correspond to a geographic eastern-western divide (Lynch 2014: 13). Data discussed in this article are drawn from languages of lower-level sub-groups of both the Western Malekula and Eastern Malekula linkages. Map 1 shows the present-day locations of these languages.

In terms of their dominant typological characteristics, the sample languages are SV/AVO in their word order, and display nominative-accusative alignment, evident in agreement morphology on the verb. Main verbs typically carry a series of affixal inflections, with prefixes that index the (S/A) subject, as well as coding different categories of tense, aspect, and mood information. Among these categories, mood is prominent, with each language in this study being analysed as making an obligatory distinction between realis and irrealis mood. The subject prefixes can be more or less fusional, depending on the properties of individual languages. ${ }^{1}$ The languages tend to employ head-modifier patterning. Of central interest to this study are the negation strategies in the Malekula languages. In contrast to the shared characteristics described in this paragraph, negation is achieved through diverse strategies.

In examining negation, I draw upon the very substantial typological literature to generate two research aims. Firstly, I aim to describe the standard negation strategies of individual Malekula languages in a systematic way. Secondly, I seek to explain the diversity in standard negation that is evident

1 Many languages of Vanuatu are known to display an alternation in the initial consonants of verbs, with different forms of verbs being used in different grammatical contexts. Systematic consonant alternation is not a salient feature of the languages included in this sample, and indeed is almost completely absent in the languages of Malekula. 


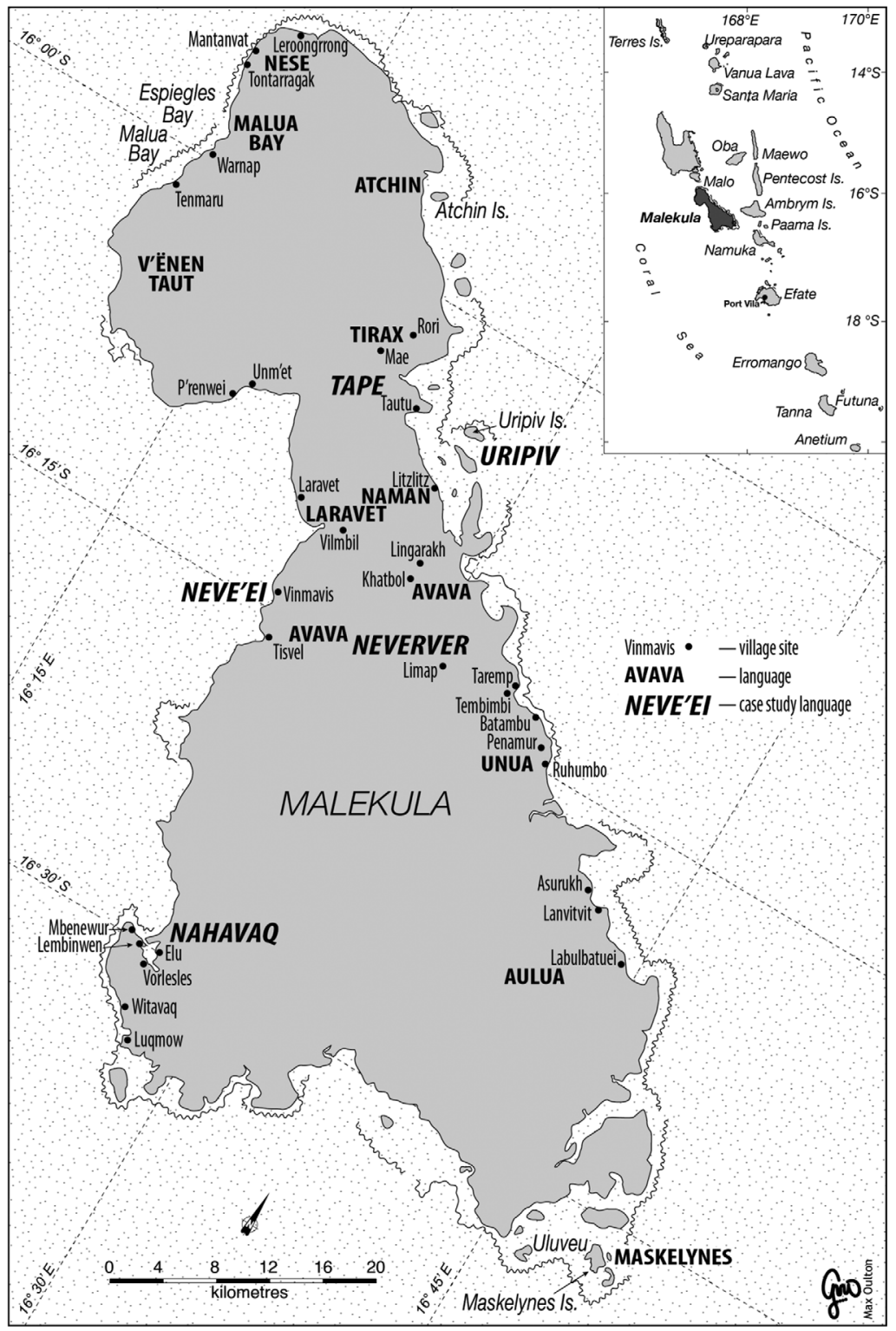

Map 1: Map of Malekula Island, Vanuatu, indicating present-day locations of 16 indigenous languages (drawn by Max Oulton). 
in the language data presented. I begin the study by defining standard negation as the area of investigation (Section 1.2). In Section 2, I then provide a brief summary of selected research in the typological literature on negation, covering the position of negative morphology (Section 2.1), the grammatical status of the negator (Section 2.2), and changes to negative morphology over time (Section 2.3). I use this literature to establish a set of locally relevant parameters for the description of Malekula language data (Section 2.4). I go on to consider the literature on negation in the Oceanic language family, and use this to generate expectations about the characteristics of standard negation in Malekula languages. In Section 3, I present six standard negation strategies attested in various Malekula languages, and I illustrate these with data from case study languages. These strategies cover a negator that occurs within a series of preverbal modifiers (illustrated by Tape in Section 3.1), double negation with an optional second negator (illustrated by Unua in Section 3.2), stable double negation (illustrated by Neve'ei in Section 3.3), double negation with an optional first negator (illustrated by Nahavaq in Section 3.4), simple postverbal negation (illustrated by Neverver in Section 3.5), and simple preverbal negation that occurs at the left edge of the inflected verb (illustrated by the Uripiv variety of the Northeast Malekula language in Section 3.6). I conclude with a comparison between the standard negation strategies in the languages (Section 4), and a consideration of the relationship between these strategies. In keeping with the findings of a recent study by Vossen \& van der Auwera (2014: 79) on negation in the Austronesian language family, I demonstrate that diversity between the Malekula languages can be understood if each standard negation strategy is viewed as an iteration of a Jespersen Cycle.

\subsection{Defining standard negation}

Addressing apprentice typologists, Whaley (1997: 226) offers a general prose description of the function of negation as being "to deny the actuality of an event or some portion thereof”. We might also employ logical expression to describe the function of negation. Propositional logic treats negation as a reversal of the truth value of a proposition $p$ to give $\sim p$ (not $\mathrm{p}$ ), where $\sim p$ is true if and only if $p$ is not true (see, e.g., Horn 1989: xiii). Such a definition establishes a very simple and symmetrical opposition between affirmative and negative. Given that there are often asymmetries between pairs of affirmative and negative constructions (see, e.g., Miestamo (2005) on asymmetries of form and Horn (1989) on asymmetries of meaning), more considered definitions accommodate evidence from natural language by reducing the requirement for 
symmetrical opposition. Miestamo's (2005: 42) definition of standard negation illustrates this reduced or qualified formalism:

\begin{abstract}
A SN [standard negation] construction is a construction whose function is to modify a verbal declarative main clause expressing a proposition $p$ in such a way that the modified clause expresses the proposition with the opposite truth value to $p$, i.e. $\sim p$, or the proposition used as the closest equivalent to $\sim p$ in the case the clause expressing $\sim p$ cannot be formed in the language, and that is (one of) the productive and general means the language has for performing this function.
\end{abstract}

Miestamo's (2005) definition blends the functional with the structural, by employing a deliberately loose functional definition, and by delimiting the structures in which negation is considered. Thus, standard negation is observed in clauses that are verbal as opposed to non-verbal. Relevant clauses are declarative as opposed to interrogative or imperative, and negation is considered in main clauses as opposed to subordinate clauses. All of the constructions which are excluded by this definition have been associated with alternative negative strategies in at least some languages (Miestamo 2005: 45). In addition to being "standard" because it is the strategy associated with simple declarative clauses, negation is "standard" in that it is a productive and general process. This means that the standard negation strategy is widely applied to members of the verb class with a fairly consistent semantic effect (Miestamo 2005: 44).

\title{
2 Typological frameworks
}

The typological literature on standard negation that is of most relevance to this article clusters around three main considerations, these being the position of negative morphology, the grammatical status of the negator, and changes to negative morphology over time. Key work in these three areas is outlined below. Relevance to the study of Malekula languages is made explicit, and the typological literature is used as a starting point to formulate parameters for comparing standard negation in the sample languages. Consideration of a fourth area of interest, asymmetries that arise in the formation of negative structure (see Miestamo 2005), is beyond the scope of the current work, but continues to be examined.

\subsection{Position of negative morphology}

Pre-typological work on the position of negative morphology identifies a tendency for the negator to be placed early in the negated construction (Jespersen 
1917: 5). Subsequent typological studies confirm this tendency, observing that the negator is more likely to be placed in a preverbal position than elsewhere, irrespective of basic word order (Dahl 1979: 91; Dryer 1988: 98, 2011a, b, c). Dahl (2010: 16, 24) identifies a shared leftward tendency for both free and bound negators. Horn (1989: 292) explains this general tendency in terms of the function of negation, commenting that the leftward position of negation allows it to "precede the material over which it has scope". Horn (1989: 311) offers a cognitive motivation also, proposing that when the negator is signalled early in a construction, it is easier to process the negative proposition. Jespersen's claim that negation occurs early "for the sake of clearness" (Jespersen 1917: 5) appears to anticipate this cognitive motivation. In spite of the strong tendency towards a leftward position, it should be noted that there are languages that place negators elsewhere in the clause.

In considering standard negation, the preferred position of the negator, formulated as NEG FIRST by Horn (1989: 293), specifies the sequencing of negation in relation to the verb, over which it has scope. Vossen \& van der Auwera (2014: 61) comment that "a preverbal position need not be immediately before the verb and it may even be the clause-initial position" while "a postverbal position need not have the negation immediately following the verb and the negation may take up a clause-final position". With this in mind, we could examine the position of the negator in relation to the clause as a larger structural unit; however, in the languages included in this study, it is the inflected verb, rather than the whole clause, that is relevant.

Payne (1985: 227) makes use of the phrase "internal negative" to describe negators which occur within a series of verb affixes. We can extend this line of thought to make a contrast between internal and external negators, capturing the distinction between languages that place the negator within the series of either bound or free modifiers of the verb, and those that place the negator at the beginning or end of this verbal morphology. Here, the term "edge" negator is used in contrast with "internal" negator, and the relevant "edge" references the boundary of the inflected verb, rather than the clause boundary. ${ }^{2}$

Whether positioned at the edge of the modified verb, or internally, a further distinction can be made classifying the position of the negator before the verb root ("left"), or after the verb root ("right"). This then provides four options for position, with double negation languages employing more than one of these in the expression of negation. The four positions are presented in (1).

2 The term "external negation" is avoided as it has been used to describe negation that is external to a clause, as Dahl (1979: 80) notes with the example It is not the case that it is raining. 


\section{[Left Edge] [Left Internal] veRB [Right Internal] [Right Edge]}

\subsection{Status of negative morphology}

The classification of negators by form is an issue that most typologists working in the area of negation have considered, with a free/bound distinction typically being made. In Payne’s (1985: 206-233) syntactic typology of standard negation, he distinguishes between free "negative particles" and bound "morphological negatives”. Dahl's (1979) typology of negation separates bound morphological negation from all other types. Dahl (1979: 83-84) offers a number of criteria for the classification of a negator as morphological, including position (comparatively near to the verb root), integration with other morphemes, responsiveness to morphophonemic processes, and responsiveness to other processes that apply at the level of word. Criteria for syntactic negation include the potential for independent inflection, movement, and even a separate orthographic representation (Dahl 1979: 83-84), although orthography might be regarded as a somewhat unreliable measure.

In spite of the wide use of a free/bound distinction in classifying negative morphology, it is not without problems, particularly when applied to languages that display double negation, which is the case for many languages of Malekula. This is because each negator in the construction has individual behavioural properties. The free/bound classification also sets aside the potential for variation in the form of negators. Such variation may see a negator behaving as free in some contexts, and as bound in others. Miestamo (2005: 19) abandons the free/bound distinction, claiming that it has the potential to "obscure some similarities and differences between constructions”. Essentially, Miestamo argues that the free/bound distinction classifies some very similar negation strategies into separate categories, and classifies some very different strategies into the same category. Negators in the sample Malekula languages are problematic in that many negators display properties of both bound and free morphology.

In this study, consideration of whether a given negator is free or bound is not a central concern. Rather, emphasis is placed on variation that negators may display. The negator may be completely invariant, with a stable phonological form, and a predictable presence in standard negation clauses. Alternatively, the negator may vary in its phonological form or in its presence in clauses. Variation in form could be triggered by automatic processes that apply broadly in the language, and are therefore explainable at the level of phonology, as instances 
of phonologically conditioned sound change. Alternatively, variant forms of a negator may reference their morphological context, and therefore constitute morphologically conditioned sound changes. An extreme version of morphosyntactic variation would be a language that displays a paradigm of negators, organised on the basis of, for example, person/number categories. Possibilities for variation in form are presented in (2).

(2) a. Invariant negator

Invariant

b. Variant negator

Variant(Phon) Phonologically conditioned NEG allomorph

Variant(Gram) Morphologically conditioned NEG allomorph

c. Multiple negators

Paradigm Paradigm of grammatically contrasting negators

The distribution of a particular negator in a standard negation clause, including its presence, absence, or position, may be explained by nonlinguistic factors, such as age or formality. Such variation can lead to changes in the expression of standard negation over time, and these changes are considered further in Section 2.3. As data from Malekula languages is explored, negator variation emerges as an area of diversity.

\subsection{Changes to negative morphology over time}

The most influential observation regarding negators through time is known as the Jespersen Cycle. The Jespersen Cycle is a hypothesis formulated to account for changes in the strategy employed to encode standard negation. In his monograph Negation in English and other languages, Otto Jespersen (1917: 4) made a much quoted observation on the diachronic tendencies of negative morphology:

The history of negative expressions in various languages makes us witness the following curious fluctuation: the original negative adverb is first weakened, then found insufficient and therefore strengthened, generally through some additional word, and this in its turn may be felt as the negative proper and may then in course of time be subject to the same development as the original word.

Jespersen's observation, applied to French and English among other languages, echoes earlier work by Meillet (1912, cited in van der Auwera 2010: 76) on French, and Gardiner (1904, cited in van der Auwera 2009: 42) on Coptic and 
Demotic Egyptian. In each case, a process of change is observed. In its simplest form, Jespersen's cycle (so named by Dahl (1979: 88)) sees the standard negation strategy for a language move through a series of patterns. In negation in French, the negator ne (Stage 1 ne) is reinforced by the emphatic pas 'step' (Stage 2 ne... pas), and then the original negator falls out of use (Stage 3 pas), as is the case in varieties of modern colloquial French. This simple three-stage process is presented by van der Auwera (2010: 76, 78), who demonstrates that the stages do not necessarily happen in a tidy sequential manner, but that multiple stages are observable in the progression from one negative pattern to another, and that the stages may well be contemporaneous.

Jespersen (1917: 5) motivates changes to the standard negation pattern with the phonetic weakening of the original negative. The negator is "made to be accentually subordinate to some other notion; and as this happens constantly, the negative gradually becomes a mere proclitic syllable (or even less than a syllable) prefixed to some other word" (Jespersen 1917: 5). In this context, a strengthening morpheme is introduced. Other linguists, Meillet (1912, cited in van der Auwera 2010), van der Auwera (2010), and Vossen \& van der Auwera (2014) in particular, offer a semantic motivation for the change. Van der Auwera explains that the use of an emphatic element in negation is very common in the world's languages. This emphatic element collocates so routinely with the standard negator, that over time it loses its emphatic value and is thus reanalysed as being part of the standard negation strategy (van der Auwera 2010: 77). A Jespersen Cycle then, can be understood as follows (van der Auwera 2009: 58):

Either through the repetition of a clause negator or through the reanalysis of something else, one arrives at a bipartite negative construction, which is either emphatic or neutral. In the bipartite construction, the new negator can oust the old one, and at both the bipartite or the new simple stage the emphasis can disappear.

Additionally, negation cycles that move from double to triple negation have been identified (see, e.g., van der Auwera 2009: 65-66, Vossen and van der Auwera 2014: 76-78). Because of the variation in how the negation cycle is motivated, and how it unfolds both through time, and though language systems, it is thus more aptly named in the plural as the "Jespersen Cycles" (van der Auwera 2009).

Evidence from the sample languages of Malekula contributes to the growing literature on the Jespersen Cycles, as the languages can be seen as displaying different stages of their own cycles. Variation in the presence of negators, as evidenced through choices made by speakers with contrasting social characteristics, suggests that at least some of the languages are undergoing active processes of change. 


\subsection{Typological commentary on negation in the Oceanic language family}

The typological literature on negation in the Oceanic language family is sparse, comprising only one dedicated volume edited by Hovdhaugen \& Mosel (1999), which primarily surveys New Caledonia and Loyalty Islands languages. Typological work on Vanuatu appears some years earlier however, with Early's (1994a, b) description of negation in the Lewo language of Epi Island in Vanuatu. Early (1994b: 415-416) looks to the Jespersen Cycle to account for Lewo's unusual tripartite negation, and evidence from Lewo has contributed significantly to the understanding that phonological reinforcement does not necessarily motivate cyclic change in negation, and to the understanding that there are multiple outcomes for such cyclic change (see van der Auwera 2009 on both of these points).

Early compares negation in Lewo with patterns in other Vanuatu languages, and offers a summary of his data (Early 1994a: 89):

This review indicates a wide range of negative forms and types for these languages, perhaps wider than might have been expected, even among the more closely related NCV [North Central Vanuatu] and Epi languages in particular [...] there is a high incidence of discontinuous negative marking within NCV, and this pattern is only sporadically attested elsewhere in Oceanic. For NCV, there is also an equally high degree of apparent non-cognancy in the forms that appear, which will render any attempts to reconstruct negative marking within NCV particularly difficult.

Early's study anticipates the observations made in Lynch, Ross \& Crowley's (2002) volume The Oceanic languages. They present a general typological overview of Oceanic languages, as well as a reconstruction of aspects of the ancestral Proto-Oceanic. More than 40 grammar sketches are offered, extending geographically from Manus Island in the Bismarck Archipelago to the Marquesan Islands in French Polynesia, including two Malekula languages. A number of generalisations are made in the typological section on negation, including the opening observation that negation is tied closely to the form of subject and tense/aspect/mood marking (Lynch et al. 2002: 51). The typical position of the negator is after the subject and tense/aspect/mood morphology and before the verb stem, being Left Internal. On double negation, Lynch et al. (2002: 51-52) observe that discontinuous negation is widely distributed through the language family, typically comprising a preverbal element and a postverbal element. They go on to comment that the negative elements show a lot of variation in form, and suggest that this might be interpreted as evidence of the replacement of one 
negative particle by another (Lynch et al. 2002: 88). Such observations are consistent with the Jespersen Cycles, which can see non-negative particles coopted into the expression of negation. The scattered geographic distribution of double negation is interpreted as evidence of the parallel development of double negation through the Oceanic region (Lynch et al. 2002: 52), again, consistent with the Jespersen Cycles, as changes to negation appear to involve language internal processes.

Budd's (2010) comparative-historical study of negation in Bierebo and other languages of Epi Island revives Early's (1994a, b) research. Budd's paper offers a detailed descriptive account of negation in Bierebo, and delves into the history of the negators in Bierebo and the other Epi languages. His research supports the general observation of diversity in negation that was made by Early, and he identifies four distinct grammaticalization pathways into negator status. These multiple pathways support the replacement hypothesis of Lynch et al. (2002).

Drawing on research from Vossen's doctoral thesis, Vossen \& van der Auwera's (2014) study is the most recent contribution to the study of negation in the Oceanic language family. On a far larger scale than any previous typological study in Oceanic, Vossen \& van der Auwera survey 409 Austronesian languages. Specifically interested in double negation, and whether it might be compatible with the Jespersen Cycles, they find double negation in 81 of their sample languages (Vossen \& van der Auwera 2014: 57). Of these 81 languages, 65 are Oceanic, and of these 65, 63 are spoken in Melanesia (Vossen \& van der Auwera 2014: 61). This finding serves as a corrective to the claim of Lynch et al. that double negation is widespread in Oceanic. We might rather describe the double negation as being commonly found in the Western Oceanic languages (as classified by Ross et al. 2011: 7). In seeking to examine the extent to which double negation in the Austronesian language family is compatible with the Jespersen Cycle hypothesis, Vossen \& van der Auwera (2014: 79) conclude in the affirmative.

In sum, the literature on negation in the Oceanic languages, and on the languages of Vanuatu themselves is somewhat limited, but it is coherent in that it sets up an expectation of diversity in the forms of standard negation. Preverbal negation and double negation are the most likely patterns of negation, but we should not be surprised to find diverse negation patterns and indeed noncognate negators in geographically close languages, such as the languages of Malekula. Recent work on double negation in the higher-level Austronesian language family has found the Jespersen Cycles to be particularly relevant among the languages of Vanuatu, allowing for the explanation of standard negation patterns in closely related languages. 


\section{Six types of standard negation in the languages of Malekula}

In describing standard negation in the languages of Malekula, I identify six broad types of negation strategy. I present a case study language to exemplify each type. In places, my account is somewhat different from the source analyses, as I attempt to arrange the data in a format that draws out features of comparative and typological interest. I describe the case study language in terms of the position of negators in relation to the verb, and in terms of variation in the form of the negator(s), and I look for evidence of diachronic change in the available data. In presenting the data, I employ a Standard Malekula Orthography (SMO), detailed in Appendix A.

\subsection{Simple Left Internal negation}

A number of Malekula languages employ a single negative particle, located within a series of preverbal modifiers, as their standard negation strategy. These languages include Aulua of the Central East subgroup, the Maskelynes language of the Southeast Malekula subgroup, and neighbours Tape and V'ënen Taut, classified as Northwest Malekula languages. ${ }^{3}$ Table 1 summarises the forms of these preverbal negators.

Table 1: Malekula languages displaying Left Internal negation.

\begin{tabular}{|c|c|c|}
\hline Language & Standard negation & Source \\
\hline Aulua & VERB & $\begin{array}{l}\text { Paviour-Smith (2005), Paviour-Smith \& } \\
\text { Makenzie (2005) }\end{array}$ \\
\hline Maskelynes & $s V-$ & Healey (2013) \\
\hline Tape & sk(e)-/ska- VERB & Crowley (2006b) \\
\hline V'ënen Taut & (kh)a- & Fox (1979), Dodd (2014) \\
\hline
\end{tabular}

Data from the Tape language illustrates the pattern of Left Internal negation. The bound preverbal negator occurs among a series of prefixes that attach to the verb, following morphology coding information about the subject, and aspectual

3 All subgrouping classifications are attributed to Lynch (2014). 
contrasts, and preceding morphology coding number contrasts (Crowley 2006b: 152-154). The language is interesting in that it displays negator number agreement. The form ske- [NEG] occurs in the contexts of singular and impersonal subjects, while ska- occurs in the context of non-singular subjects. Singular and impersonal subjects are unmarked for number (represented by $\emptyset$ to identify the structural slot for number), while dual and plural subjects are marked with the prefixes $r$ - and $n$ - respectively.

(3) Tape (Northwest/Peripheral Western/Western Malekula Linkage)

a. I-Ø-mekar.

3.R-SG-work

'(S)he works.' (Crowley 2006b: 153)

b. I-ske-Ø-mekar.

3.R-NEG.SG-SG-work

'(S)he is not working.' (Crowley 2006b: 153)

c. Dë-n-rëngdo.

1NSG.INCL.R -PL-know

'We (PL.INCL) know.' (Crowley 2006b: 153)

d. Dë-ska-n-rëngdo.

1NSG.INCL.R -NEG.NSG-PL-know

'We (PL.INCL) do not know.' (Crowley 2006b: 153)

e. I-ska-r-khuos mili...

3.R-NEG.NSG-DU-be.strong again

'They two were not strong (enough)...' (Crowley 2006b: 72)

Although the singular and plural negators are stable in form, example (4), extracted from Crowley's Tape corpus, indicates that the singular negator is subject to phonological constraints. In the context of a vowel-initial verb stem, $s k e$ - reduces to $s k$-. This process falls under an automatic alternation identified by Crowley, whereby "when two vowels are brought together over a morpheme boundary [... and] neither of the two vowels is a schwa, the first of the two vowels is systematically lost" (Crowley 2006b: 110).

(4) I-de-sk-Ø-ivin echëkhë-n elakh esen.

3.R-CONT-NEG.SG-SG-go goal-3SG husband POSs.3SG

'She has not yet gone to her husband.' (Crowley 2006b: 150)

In the non-singular, there is always either the dual $r$ - or the plural $n$-intervening between the negator and a vowel-initial stem, meaning there can never be two sequential vowels over the negation-number morpheme boundary. Thus the 
contrast between singular and non-singular negator forms is maintained in all environments. ${ }^{4}$

The standard negator in Tape can be described as a variant morpheme, subject to grammatical constraints (Variant(Gram)). In the available data, Tape displays no evidence of change in its standard negation strategy.

(5) Standard negation in Tape

Modern SN SUBJ-NEG:NUM-NUM-VERB

\subsection{Double negation: Optional NEG2}

One language of Malekula has been analysed as employing a standard negation strategy of double negation where the second negator (NEG2) is optional. This is Unua (Pearce 2015), classified as a Central Eastern Malekula language (Lynch 2014: 13). Like the single preverbal negators of Tape discussed in Section 3.1, Unua's first negator (NEG1) seb- [ $\mathrm{se}^{\mathrm{m}} \mathrm{b}$-] is Left Internal, occurring within a series of structural positions where speakers code the person and number of the subject, as well as tense/aspect/mood contrasts. NEG2 takes the invariant phonological form rre [re], and it is positioned after the verb root.

(6) Unua (Central East/Eastern Malekula Linkage)

a. No-vekhut...

1sG.R-go.to.shore

'I came ashore...' (Pearce 2015: 398, Footnote 8)

b. No-seb-vekhut rre iog.

1SG.R-NEG1-go.to.shore NEG2 there

'I didn’t go ashore there.' (Pearce 2015: 398, Footnote 8)

NEG1 displays phonologically determined allomorphy, varying from the base form $s e b$-, to the shortened se-, preceding some bilabial consonants (Pearce 2015: 215). NEG1 seb-also occurs as sebV- (Pearce 2015: 514). While the final vowel is

\footnotetext{
4 An anonymous reviewer raises the question of whether the negator inflected for number could be considered a verb. Number marking is distributed over in two preverbal positions in other Malekula languages (see, e.g., Neverver in Barbour 2012: 165-166), which perhaps makes the pattern of number agreement in Tape less surprising. A verbal analysis would be inconsistent with the position of non-singular morphology in other structures in Tape. Nuclear (compounded) serial verbs produce contiguous sequences of verb roots, where only the first root is inflected with preverbal affixes (Crowley 2006b: 160-162).
} 
described as being phonologically conditioned, the conditions are not detailed by Pearce. In my observations of Pearce's recorded textual data, 12 out of 13 instances of $s e b V$ - precede a verb root that begins with a complex onset. The additional vowel would allow for the simplification of the root onset, when syllabification occurs. ${ }^{5}$ How widespread this pattern is in Unua is unclear, but supposing the allomorph sebV-is indeed phonologically conditioned, this would make Unua's NEG1 tentatively Variant(Phon).

a. I-se-vos-i rre mu rre

3SG.R-NEG1-pick.up-TR NEG2 CONT NEG2

'They couldn't pick her up (lit., s/he did not pick him/her up again).' (Pearce 2015: 329)

b. Re-sebe-vsekhn-i rre khina

3PL.R-NEG1-teach-TR NEG2 1SG

'They did not teach me...' (Pearce 2015: 167)

In almost all examples provided by Pearce, rre is the final element of the modified verb, followed by the object noun phrase, if one is present. A footnote by Pearce, however, offers two examples of natural speech which display the sequence rre mu where $m u$ is glossed 'again', providing a continuative negative 'no longer, not again' meaning (Pearce 2015: 328). Pending further evidence, we can simply classify the position of NEG2 as Right.

The $m u$ 'Continuative, again' particle patterns with negation in three different ways, including rre mu, mu rre, and rre mu rre, as shown in example (7a). This pattern suggests emphatic triple negation; however, the doubling of NEG2 rre depends on the presence of the non-negative particle $m u$, and on this basis, cannot be considered "standard" negation in Unua.

Concerning NEG2, this phonologically invariant negator has a distribution pattern that appears to be grammatically driven. Pearce (2015: 520) observes the presence of rre with non-irrealis moods, and the absence of rre with irrealis mood. This patterning is not absolute, with a small number of counterexamples in Pearce's data. Thus, Pearce reports that irrealis clauses may also contain rre, and that non-irrealis clauses may also lack rre. NEG2 might then be described as optionally variant, where variation can be explained by grammatical conditioning, i.e., Variant(Gram).

5 The insertion of vowels and re-syllabification of inflected verbs is a core part of the phonotactic organisation of the Neverver language (Barbour 2011, 2012: 49-59). 
(8) Standard negation in Unua

$\begin{array}{ll}\text { Modern SN } & \text { SUBJ-NEG1-V-(NEG2) } \\ \text { Possible future SN } & \left.\text { SUBJ-NEG-V or SUBJ-NEG1-V-(NEG2 } 2_{\text {NON-IRREALIS }}\right) \\ & \text { SUBJ-NEG1-V-NEG } 2_{\text {NON-IRREALIS }} \text { or SUBJ-NEG1-V-NEG2 }\end{array}$

The pattern of variation for Unua as it is spoken today suggests multiple possible futures for standard negation. NEG2 might disappear entirely from the language, reversing the apparently unidirectional change which is implied by the Jespersen Cycle. Asymmetry in the language may strengthen, and NEG2 might disappear entirely from irrealis coded clauses, while remaining optionally for non-irrealis clauses. Alternatively, NEG2 may stabilise and become an obligatory element of non-irrealis-coded clauses, or indeed of all clauses in the language, moving the language towards stable double negation. Further, the doubling of NEG2 may generalise away from the rre mu rre structure, and be used in a wider range of grammatical environments, producing standard triple negation.

\subsection{Stable double negation}

Consistent with previous research and typological predictions on negation in the Melanesian languages of the Oceanic family, the most widely attested pattern of standard negation among known Malekula languages is stable double negation. Relevant languages are presented in Table 2, although this list is by no means exhaustive. Malekula linguists tend to treat NEG1 as a bound morpheme, and NEG2 as a free morpheme. This appears to be because NEG1 often varies in terms of its vowel, which may undergo a harmonising process, responding to its surrounding phonological environment. In contrast, NEG2 is largely invariant.

Table 2: Double negation in Malekula languages.

\begin{tabular}{lllll}
\hline Language & \multicolumn{2}{l}{ Standard negation } & Source \\
\hline Atchin & $s V$ & VERB & te & Capell \& Layard (1980) \\
Avava & $s a-$ & VERB & $m u$ & Crowley (2006a) \\
Larevet & $s V-$ & VERB & $-(\ddot{e}) v$ & Barbour (field notes) \\
Malua Bay & $p(e / \ddot{e})-$ & VERB & te & Wessels (2013) \\
Naman & $s V-$ & VERB & si & Crowley (2006c) \\
Nese & $(s) b e-$ & VERB & te & Lana Takau (personal communication) \\
Neve'ei & $s V-$ & VERB & si & Crowley (2002), Musgrave (2001, 2007) \\
\hline
\end{tabular}

Comment is required on my inclusion of the Nese language on this list, as Vossen \& van der Auwera (2014: 76) treat the language as displaying optional 
triple negation. In his preliminary analysis of a very small corpus of Nese data (Crowley 2006d: 70), Crowley records much variation in the expression of negation in what appear to be elicited constructions in Nese, and considers the possibility that the language might display triple negation with preverbal morphemes se- and be-, and the postverbal morpheme te. Doctoral student Lana Takau (personal communication), at Newcastle (Australia), working with a substantially larger recorded Nese corpus, finds more consistency in the data, and treats the same preverbal morphemes as an unanalysed NEG1 of the form sbe-. Looking to the neighbouring and related language varieties of Espiegle's Bay (Holmes 2014) and Malua Bay (Wessels 2013), we find that both employ $s V$ - as their irrealis/future morpheme. Likewise, Nese employs se-, alternating with je[te-], for irrealis mood (Crowley 2006d: 68-69). This suggests an analysis of asymmetry in Nese, where negative clauses (with NEG1 be-) are all coded for irrealis mood (with IRR $s(V)$-). Given that alternative analyses readily available, it seems unlikely that triple negation, hypothesised by Crowley and cited by Vossen \& van der Auwera (2015: 76), can be sustained for Nese.

Stable double negation is illustrated with data from the Neve'ei language, where the two-part negator comprises a first element $s V$-, which precedes the verb, and a second element si, which follows the verb (Crowley 2002: 645, Musgrave 2007: 51).

(9) Neve'ei (Unclassified/Western Malekula Linkage)

a. Ne-leh nourour nge.

1sG.R-see island DEM

'I saw the island.' (corpus Crowley/Musgrave/Barbour: vnm_27.5)

b. No ne-se-leh-si D.

1SG 1SG.R-NEG1-see-NEg2 D.

'I didn't see D.' (corpus Crowley/Musgrave/Barbour: vnm_10.31)

NEG1 can be described as Left Internal, positioned after subject/mood prefixes, and before the verb. Musgrave's (2007: 53) analysis indicates that NEG2 occupies the Right Edge position. NEG2 always follows the transitive suffix - $V n$ if present, and likewise it follows the final element in a serial (compound) verb construction (Musgrave 2007: 55-56, 80-87). Musgrave argues that if the morpheme en, which is a common instantiation of the transitive suffix, follows NEG2, it functions not as an indicator of transitivity, but rather to introduce an oblique phrase. $^{6}$

6 The transitive suffix appears to attach to inherently intransitive verbs, and produces a valence shift from 1 to 2 . Inherently transitive verbs like 'see' occur without the transitive suffix. 
(10)
a. At-su-suli dem-en-si niar nge.

3PL.R-NEG1-burn still-TR-NEG2 garden DEM

'They are not still burning the garden.' (Musgrave 2007: 56)

b. At-su-luv mah-an-si nedam.

3PL.R-NEG1-plant finish-TR-NEG2 yam

'They didn't finish planting the yams.' (Musgrave 2007: 81)

c. Ne-se-vwer mah-si en ar.

1SG.R-NEG1-say COMPL-NEG2 OBL 3NSG

'I have not said everything about them.' (corpus Crowley/Musgrave/

Barbour: vnm_10.86)

In examples $(10 a-c)$ we can observe that NEG1 is affected by a process of vowel harmony, where the initial vowel of the verb root regressively influences the shape of the NEG1 vowel. This means that NEG1 is a variant morpheme, subject to morphologically conditioned phonological constraints (Variant(Gram)).

Departing from standard negation slightly, the second negator -si is found to be replaceable in one particular grammatical context. When the negative meaning shifts from 'not' to 'not yet', NEG2 is replaced by -vang.

(11) Bwe-se-leh-vang natnomomokh nge nokhon.

3SG.IRR-NEG1-see-YET girl DEM face

'He wouldn't have seen the girl's face yet.' (corpus Crowley/Musgrave/ Barbour: vnm_28.25)

The morpheme 'yet' differs from NEG2 in that it carries concordant marking for transitivity:

(12) No-so-nonong-on-vang-an nemangarian tno.

1SG.R-NEG1-finish-TR-YET-TR work 1sG.POSS

'I haven’t finished my work yet.' (Musgrave 2007: 52)

Further, data from the Neve'ei corpus shows that vang can also function independently of negation, in the same structural position, as a politeness device:

(13) Nat-ung ar btwit-vwelem vang sakhan no utne. child-1SG.POSS PL 2PL.IRR-come please GOAL 1sG here 'My children, please come here to me.' (corpus Crowley/Musgrave/ Barbour: vnm_29.25) 
The replaceability of NEG2 in the vang 'not yet' context suggests that outside of standard negation, the comparatively greater burden of negative meaning rests with NEG1. Elsewhere, however, NEG2 simply combines with similar types of aspectual morphology.

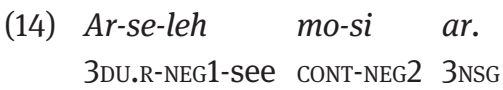

'They didn't see them anymore.' (Musgrave 2007: 114)

There is some diachronic data available for Neve'ei, in the form of transcriptions made by British anthropology student A. Bernard Deacon in the 1920 s (1934; included in the corpus Crowley/Musgrave/Barbour: vnm_01 to 05). Deacon's texts contain few examples of negation, but those that are recorded are entirely consistent with Musgrave's findings related to data collected some 80 years later, including vowel harmony patterns. Examples $(15 \mathrm{a}, \mathrm{b})$ provide a standardised representation of Deacon's data, and a modern translation to Deacon's original transcriptions.

a. Mamwe gusughusghussi nembat. (Original)

Mamwe, ku-su-khus-khus-si nebat. (SMO)

father 2SG.IRR-NEG1-DUP-hit-NEG2 Nebat plant

'Father, do not strike the Nebat (plant).' (Deacon 1934: 731; corpus Crowley/Musgrave/Barbour: vnm_03)

b. Ar selehsi. (Original)

Ar-se-leh-si. (SMO)

3DU.R-NEG1-See-NEg2

'They couldn't see (their child).' (Deacon 1934: 731; corpus Crowley/ Musgrave/Barbour: vnm_03)

Given this historical evidence, we can conclude that double negation is stable in Neve'ei, and has been so for several generations of speakers.

(16) Standard negation in Neve'ei

Older SN SUBJ-NEG1-V-NEG2

Modern SN SUBJ-NEG1-V-NEG2

\subsection{Double negation: Optional neg1}

Two languages have been identified that display double negation with optional NEG1. These are the Nahavaq language spoken in southwestern Malekula, and the 
Tirax language of northwestern Malekula. In both cases, an older pattern of NEG1 - VERB - NEG2 appears to be giving way to a modern pattern of simple postverbal negation.

When double negation is expressed in Nahavaq, standard negation comprises a prefix $s$ - and a postverbal particle veq [ve?] (Dimock 2009: 141). The first negator immediately follows the subject/mood prefix. In all attested examples, NEG1 attaches to the verb stem, and it is thus Left Internal. NEG2 is positioned to the right of the verb stem, and can be followed by postverbal modifiers, making it Right Internal. The pairs below are structural equivalents from Dimock's recorded oral text corpus, some of which are reproduced in her grammar.

(17) Nahavaq (Southwest/Peripheral Western/Western Malekula Linkage)

a. No-ronghur.

1SG.R-know

'I know.' (corpus Dimock: nhv_t.07128.229)

b. No-s-ronghur veq.

1SG.R-NEG1-know NEG2

'I didn’t know.' (Dimock 2009: 264)

c. Re-les noqonin i-lim.

3PL.R-see palm 3R.sG-five

'They saw five of them.' (corpus Dimock: nhv_t.mr01.041)

d. $R$ u-s-les veq nibetep nin.

3DU.R-NEG1-see NEG2 breadfruit DEM

'They didn't see the breadfruit.' (Dimock 2009: 195)

Examples from Dimock (2009) show NEG2 co-occurring with a variety of preceding postverbal modifiers, including malas 'yet', which is positionally flexible, and may either precede or follow veq. NEG2 also co-occurs with following postverbal modifiers, such as lis 'again', illustrated below.

(18) Nigin da-s-qan-qan veq lis nimahal en.

1PL.INCL 1PL.INCL-NEG1-DUP-eat NEG2 again fish DEM.ID

'We can't eat fish anymore.' (corpus Dimock: nhv_t.07117.133)

Nahavaq's double negation appears to be undergoing change, in the direction of reduction to a single postverbal negator. Dimock (2009: 195) observes that some speakers omit the $s$ - prefix. She associates this with child language and younger speakers more generally, but notes that older speakers also occasionally omit the first negator (Dimock 2009: 142, 195). There are few examples in her recorded corpus of the omission of NEG1, due primarily to constraints 
around the age of project participants; however one older speaker produces this innovative construction. Dimock's example is repeated in (19).

Qet naqayew ke-luwe-lu veq.

then pudding 3SG.IRR-DUP-vomit NEG

'Then the pudding won't overflow.' (Dimock 2009: 142)

Dimock's observation about the loss of $s$-, particularly among younger speakers, suggests that the prefix may be in the early phases of falling out of use. In contrast, postverbal veq has functions that extend beyond standard negation, with veq serving as a general constituent negator (Dimock 2009: 195-197). In other Malekula languages, these functions are typically fulfilled by negative existential verbs. ${ }^{7}$

a. Nimorot sut i-long taq veq lis.

man NSP 3sG.R-go after NEG again

'There wasn't anyone coming behind (lit., someone did not go after again).' (corpus Dimock: nhv_t.mahr01.046)

b. Kinang veq.

1SG NEG

'It wasn’t me.' (corpus Dimock: nhv_t.kok03.009)

NEG1 is subject to automatic degemination in the environment of a following [s]. As Dimock (2009: 142) points out, this means that the negated verb is then "phonologically indistinguishable from the same base without the negative prefix". Examples (21a-b) display the same sentence rendered in two ways. Although this particular example is an imperative rather than a declarative clause, the negation strategy is the same.
a. Ku-sarlis
veq niqisbwet ti-nug [...]
2SG.IRR-exchange NEG grass.skirt Poss-2SG
b. Ku-s-sarlis
veq [...]
2SG.IRR-NEG1-exchange NEG2

'Don’t trade your grass-skirt [...]' (Extract from Dimock 2009: 132)

7 In Neverver, the expression 'It wasn't X' would take the form $X i$-skhen, where skhen is a negative existential predicate, inflected with the 3rd person singular realis prefix (Barbour 2012: 282). In Avava, the same expression would take the form $X$ i-titik (corpus Crowley/Barbour: ava_04.Ref16) or X i-tik (Crowley 2006a: 109). 
Because NEG1 can be omitted due to degemination, it can be described as a variant morpheme, constrained phonologically (Variant(Phon)). NEG2 is invariant.

In terms of diachronic evidence for Nahavaq, Ray (1926) offers a grammar sketch of the language under the name Sinesip, based on translations of religious materials made by missionary Robert Boyd around the turn of the century. Ray (1926: 308) observes a two-part negator in the data (deslesve /de-s-les-ve/ 'we did not see') as one of his examples. Further, there is a collection of eleven historical texts, published in Deacon's (1934) volume on Malekula as Seniang. There are examples of standard negation in several of the texts, and in each clause, double negation is employed. There are no examples of NEG2 being used in non-verbal clauses, but this may be an artefact of the limited data.

(22) Nahavaq as Seniang (Deacon 1934: 152, 728)

a. Ismesve. (Original)

I-s-mes veq. (SMO)

3SG.R-NEG1-die NEG2

'She did not die.' (corpus Dimock: nhv_Deacon151_27)

b. Guslip ndal ve lis. (Original)

Ku-s-lip dal veq lis. (SMO)

2SG.IRR-NEG1-take back NEG2 again

'You can’t/won’t take it back again.' (corpus Dimock: nhv_Deacon_voices)

Based on the available evidence, standard negation in Nahavaq appears to be in the very early stages of moving from stable double negation through optional double negation, and potentially onto a single postverbal negator. NEG1 is subject to social variation, whereby certain speakers may omit NEG1 from standard negation clauses. NEG2 is an invariant negator, whose function now extends beyond the negation of verbal clauses to the negation of non-verbal constituents.

(23) Standard negation in Nahavaq

Older SN SUBJ-NEG1-V NEG2

Modern/Innovative SN SUBJ-(NEG1)-v NEG2

Possible future SN $S U B-V N E G$

Like Nahavaq, the Tirax language, which is spoken in the north-eastern village of Mae, shows evidence of an older pattern of double negation, now shifting towards a simple postverbal negator. Brotchie (2009) describes a full 
paradigm of preverbal negative subject markers that contrasts with paradigms of realis and irrealis subject markers. ${ }^{8}$

The negative subject markers co-occur with a postverbal negator [-tc], but are associated with formal speech, and emphatic negation. Elsewhere, the simple postverbal negator occurs to express standard negation. Brotchie's (2009) observations indicate a process of change. Double negation as a stable pattern of standard negation is narrowing in its functional capacity, and is being replaced by a more general pattern of simple postverbal negation.

\subsection{Simple postverbal negation}

Among the languages included in this study, only one displays a consistent simple postverbal negator, this being Neverver. Although physically located on the eastern side of the island, the language belongs to the Western Linkage. Standard negation in Neverver involves a simple postverbal negator of the form si (Barbour 2012: 279). This negator is the only morphological form available in the language to negate verbal clauses. Examples from the Neverver grammar (Barbour 2009, 2012) and associated corpus (Barbour: nvt) indicate that it follows the verb root, and the applicative suffix, but may precede other postverbal grammatical morphemes. Overtly expressed objects follow the negator. In terms of the position classification, Neverver's negation is thus Right Internal.

(24) Neverver (Central West/Western Malekula Linkage)

a. Mang i-vu.

man.ANA 3SG.R-go

'The man went.' (corpus Barbour: nvt_ks02.25)

b. Mama i-vu si.

father 3SG.R-go NEG

'The father didn't go.' (corpus Barbour: nvt_ks02.111)

c. Vinang i-khan nidam ang.

woman.ANA 3SG.R-eat yam DEM.ANA

'The woman ate the yam.' (corpus Barbour: nvt_ks16.100)

d. I-khan si nidam ang.

3SG.R-eat NEG yam DEM.ANA

'It didn’t eat the yams.' (corpus Barbour: nvt_cv03.17)

8 Brotchie's (2009) thesis is lodged with Minerva, Melbourne University's Institutional Repository, and has restricted access. While I have been granted access to the work (Amanda Brotchie, personal communication), clausal data from the thesis is not presented in this article. 
Although almost entirely invariant, I have observed that the negator reduces to a suffixing [-s] in one grammatical context (Barbour 2012: 281). The reduction occurs when the preceding morpheme is $v a[\beta a]$ 'yet' and the following morpheme is the continuous debb $\left[{ }^{\mathrm{n}} \mathrm{de}^{\mathrm{m}} \mathrm{B}\right]$. When the continuous debb form is absent, the negator takes the full form [si]. In terms of negator variation, the negator is thus variant, with morphologically determined allomorphy (Variant (Gram)). It can be noted here that Avava shares the va morpheme, while in Neve'ei the cognate morpheme is vang. In both Avava and Neve'ei, the 'yet' morpheme replaces the standard NEG2, while in Neverver it co-occurs with the postverbal negator to form va si or va-s.

\section{(25) Ar at-rongil va-s debb nemakh $L$. \\ 3NSG 3PL.R-know yet-NEG CONT denizen L.village \\ 'They don't know the people of L. yet!' (corpus Barbour: nvt_cv07.50)}

Regarding the diachrony of negation, there are two further constructions that are related to the standard negation strategy in Neverver. Commentary on these rare constructions was excluded from the predominantly synchronic Neverver grammar, but here they serve to build a diachronic picture of the language. The first construction was found in the Neverver corpus, in a recording by the oldest community member. He sings a song that contains occurrences of what appear to be double negation constructions. The speaker varies in the vowel form of both elements between [si] and [se] each time he sings the line. One iteration of this pattern is presented in (26).
(26)
$\mathrm{Ni}$-si-rongil-da se o.
1SG.R-NEG1-know-PART NEG2 song.syllable
'I don't really know.' (corpus Barbour: nvt_ki12.31)

The first negator is Left Internal, while the second appears to occupy the Right position - precisely where the sole negator is located in modern Neverver. This example of older double negation is interesting because it suggests a history of double negation in Neverver which might have been predicted on the basis of studies by other linguists in the Vanuatu region (see, e.g., Early 1994a, b; Lynch 1998; Lynch et al. 2002; Budd 2010).

The second construction was recorded only in my own field notes reporting informal interactions. A small number of young women in Limap village occasionally fronted the negator si to express the meaning 'I don't know'. They confirmed 'I don't know' as the correct interpretation, rather than the other 
possibility of 'but yes, I know', which I had initially thought they might have been saying. Where the standard expression places the negator after the verb, in the Right Internal position, the innovative form places the negator before the verb and its prefixes, on the Left Edge.

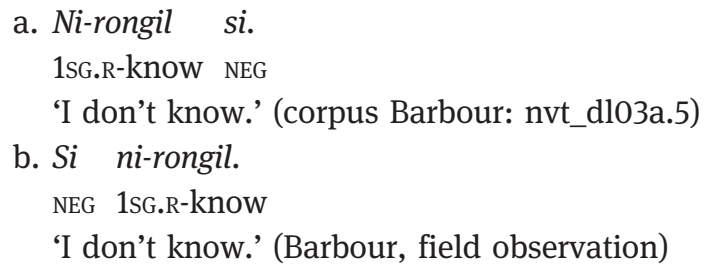

It is possible that over time, this innovative pattern might extend to other verbs, and to other grammatical contexts. Minimally, the example identifies the potential for a change in the position of the negator, as we observe a leftward shift into a new structural position preceding the inflected verb. Taken together, the assorted negative constructions in Neverver suggest a history of double negation, a period of relative stability where the NEG2 particle survives as the sole negator, and a potential future form of the language where the Right Internal morpheme shifts to a Left Edge position.

(28) Standard negation in Neverver

Older SN

SUBJ-NEG1-V NEG2

Modern/Innovative SN

(i) SUBJ-V NEG

(ii) NEG SUBJ-V

Possible future SN

NEG SUBJ-V

\subsection{Left Edge negation}

The final pattern to be described involves simple Left Edge negation. This is illustrated with the Uripiv variety of the Northeast Malekula language. Elsewhere, Uripiv has been described as sharing features with double negation languages (Early 1994a: 86, 1994b: 418, and then cited in Vossen \& van der Auwera 2014: 71). From McKerras's unpublished dictionary (2001), the standard negation strategy in Uripiv involves a simple preverbal negator of the form (s)ete. McKerras's dictionary contains more than 100 example sentences with this negator. The negator sits in Left Edge position, the first morpheme in the series of verbal modifiers. This Left Edge position has been identified as the 
innovative position for negation in Neverver, described in Section 3.5. McKerras (2001) describes the phoneme /s/ as "weak", commonly being omitted. The negator can be described as a variant morpheme (Variant(Phon)), subject to an automatic phonological alternation that is rapidly bringing about the loss of morpheme-initial /s/.

(29) Uripiv (Central East/Eastern Malekula Linkage)

a. E-vini.

3SG.R-come

'He comes.' (McKerras 2001, lexical entry evini)

b. Sete e-vini.

NEG 3SG.R-come

'He didn't come.' (McKerras 2001: [16])

c. Ete e-vini luwe.

NEG 3SG.R-come properly

'Unfortunately, he hasn't come.' (McKerras 2001, lexical entry luwe)

In my own small audio corpus for Uripiv, there are nine standard negation clauses. Negation is always expressed with the reduced form ete. Ete also is found in negated interrogative and conditional clauses, suggesting that the omission of /s/ is now more systematic than it was when McKerras was working on Uripiv Island.

(30) Ete e-les-i nanu san.

NEG 3SG.R-See-TR thing INDF

'He didn’t see anything.' (corpus McKerras/Barbour: upv_octopus.048)

Preverbal (s)ete occurs in combination with a variety of modifiers, forming sequences such as sete-wor 'not yet' and sete-mun 'no longer'. In affirmative clauses, both wor and mun are used as modifiers in a postverbal position. Mun, like Avava mu, means 'first' or 'firstly', and is employed as a politeness device in commands, as well as having other functions. Wor can mean 'further', as well as being a general emphatic device.

(31) a. Sete-wor o-rro-rro-i.

NEG-yet 3sG.R-DUP-eat-TR

'He hasn’t yet eaten it.' (McKerras 2001, lexical entry orro)

b. Nial sete-mun e-terter.

sun NEG-CONT 3sG.R-be.strong

'The sun isn't strong any longer.' (McKerras 2001, lexical entry mun) 
c. Naim pu-su mun.

house 3SG.IRR-finish first

'Let's finish the house first (lit., the house will/shall be finished first).' (McKerras 2001, lexical entry mun)

In Uripiv, (s)ete displays no variation in position, and it is not systematically used in conjunction with a second negative element to produce standard negation; however, McKerras reports that it can occur with a postverbal emphatic te, as illustrated in (32). This appears to be the source of the double negative hypothesis that has been loosely inferred from Early's (1994a,b) work. Postverbal emphatic te has not yet been attested in any of the newly recorded Uripiv data.

(32) Ete nu-majing te.

NEG 1SG.R-work EMPH

'I'm not working.' (McKerras 2001: [20])

The language variety spoken at the far north extreme of the Northeast Malekula region, the Atchin language, displays a rather different pattern. Atchin, as evidenced in texts transcribed in 1914 by John Layard (Capell \& Layard 1980), displays double negation:

(33) Mo so wosh toni te buha.

3SG.PST NEG1 carry seize NEG2 pig

'You did not carry the pig.' (Capell \& Layard 1980: 84, 238)

The component parts of Atchin's standard negation are clearly phonologically related to Uripiv's Left Edge negator, suggesting that the (s)ete negator derives from a fusing of the original preverbal negator [se] and the postverbal emphatic [te]. It seems likely that fusion occurred on the Left Edge, given examples $(31 \mathrm{a}-\mathrm{b})$, where the preverbal negator is seen to attract other postverbal aspectual modifiers. Uripiv may have bypassed the double negation stage, moving instead from simple negation, to emphatic negation, to simple negation.

(34) Standard negation in Uripiv

Hypothesised Older SN

SUBJ-NEG $V$ EMPH

Hypothesised Transition 1

SUBJ-NEG1 $V$ NEG2 Or NEG-EMPH SUBJ-V

Hypothesised Transition 2

Modern SN

NEG1-NEG2 SUBJ-V

NEG SUBJ-V 


\section{Summary: Standard negation variation in Malekula}

Having looked at six standard negation strategies in detail, it is clear that the related languages of Malekula display diversity. Given that four of the six case study languages belong to the Western Malekula Linkage, the extent of diversity is perhaps surprising. In this section, a summary of the study is provided, with comments on the position of negators (Section 4.1), variation in the form of negators that occur language-internally (Section 4.2), and variation in the form of negators that is found between the languages in the sample (Section 4.3). Reference is made to the findings of Vossen \& van der Auwera's (2014) study of negation in Austronesian where relevant.

\subsection{Negator position}

Negative elements are predominantly positioned within the inflected verb, inside independent subject and object noun phrases. In almost all languages in the sample, the preverbal negator is internal, occupying one of a series of prefix positions that are available before the verb root. For those languages in the sample with a right negator, there are instances of verbal morphology in the form of independent postverbal aspectual morphemes following the right negator in most languages. This means that the expected position for a right negator is also internal, although both Neve'ei and Unua may prove to employ the Right Edge position.

Table 3: Summary of negator position.

\begin{tabular}{llll}
\hline Language & Position & & \\
\hline Tape $(+3$ others) & Left Internal & VERB & \\
Unua & Left Internal & VERB & (Right) \\
Neve'ei (+6 others) & Left Internal & VERB & Right Edge \\
Nahavaq (+1 other) & (Left Internal) & VERB & Right Internal \\
Neverver & & VERB & Right Internal \\
Uripiv & Left Edge & VERB & \\
\hline
\end{tabular}

Neverver's sole negator, shown in Table 3 to be Right Internal, can be understood in terms of a transition from double negation to postverbal negation. Uripiv's Left Edge position is noteworthy in that the change from hypothesised historic double negation to the Left Edge position is complete. Not only that, the Left Edge negator brings with it aspectual morphemes which are located on the 
right of the verb in affirmative clauses. There is now a pathway in the language for further movement of verbal modifiers, and in time, perhaps a more radical reconfiguring of the inflected verb. ${ }^{9}$

Regarding languages with optional or obligatory double negation, the tendency observed by Vossen \& van der Auwera (2014: 62) for NEG1 to precede the verb, and NEG2 to follow the verb is supported by the data. The relevance of NEG FIRST is also apparent, with only Neverver employing a postverbal negator, although two other languages (Nahavaq and Tirax) appear to be moving in this direction with the optionality of their preverbal NEG1.

\subsection{Negator variation in individual languages}

Negators in the sample, whether part of a double negation construction or functioning as the sole expression of negation, almost all display variation. A distinction has been made between variation involving the distribution of a negator (i.e., whether it is used or not, and where), and variation in the phonological form of the negator.

Nahavaq's postverbal negator is invariant in that it occurs consistently as veq and in that it is always present in standard negation clauses. Unua, Neve'ei, Uripiv, Tape, Neverver, and Tirax all display variation in negator form. This variation can be explained in terms of automatic phonological alternations, in terms of restricted morphological triggers, in terms of category changes associated with the participant serving as the grammatical subject, and in terms of category changes associated with mood marking. The different types of variation are displayed in Table 4.

Finally, several languages show variation in the use of one part of the double negation structure, or in the position of the negator. These types of negator variation appear to be driven by contextual factors, including age of the speaker, and formality of the context. In Nahavaq, the presence or absence of NEG1 is triggered by speaker factors, with age being particularly relevant. In Tirax, the presence or absence of NEG1 paradigmatic forms is triggered particularly by formality factors. In Neverver, the movement of postverbal NEG to the Left Edge is triggered by a combination of speaker and (in)formality factors.

9 Languages in the Left Internal grouping, with a single negator, display evidence of a larger number of structural positions for person, number, clusivity, tense/mood, and aspect morphology than the other Malekula languages. Example (4) in the Tape data, as well as new field data reported in Dodd (2014) on V'ënen Taut support this claim. A closer inspection of the precise categories which are coded either before the verb, or after, is part of the author's larger study on mood and verbal morphology in the languages of Malekula. 
Table 4: Variation in negator form.

\begin{tabular}{|c|c|}
\hline Variant(Phon) & $\begin{array}{l}\text { Uripiv (automatic phonological alternation, involving presence or absence of } / \mathrm{s} / \text { ) } \\
\text { Nahavaq (automatic phonological alternation, involving degemination of } \\
\text { NEG1 /s/) } \\
\text { Unua (phonological alternations, involving reduction of bilabial sequences } \\
\text { involving NEG1 / seb-/, and the insertion of a vowel when following roots have } \\
\text { initial consonant sequences) }\end{array}$ \\
\hline Varia & $\begin{array}{l}\text { Tape (allomorphy triggered by number, involving loss of /a/ from /ska-/) } \\
\text { Unua (distribution triggered by mood, rendering NEG2 optional particularly in } \\
\text { irrealis mood contexts) } \\
\text { Neverver (allomorphy triggered by aspect, involving loss of /i/ from /si/, and } \\
\text { status change from independent to bound form) } \\
\text { Neve'ei (vowel harmony applying over boundary between NEG1 /sV-/ and the } \\
\text { verb root) }\end{array}$ \\
\hline Paradigm & Tirax (subject/negative paradigm) \\
\hline
\end{tabular}

\subsection{Comparative form variation and the Jespersen Cycles}

Having considered variation in position, and internal variation in the form and expression of negation in the sample languages, I now turn to a comparative analysis. When the negators from the sample are compared in Table 5, we can observe that there is a shared phoneme /s/ in almost all of the languages that display a preverbal negator. We can hypothesise that this shared phoneme reflects a shared ancestor negator with the shape ${ }^{\star} \mathrm{sV}$. This finding fits well with the tendency identified by Vossen \& van der Auwera (2014: 62) for the preverbal negator to be the oldest negator.

The ancestor negator ${ }^{\star} \mathrm{sV}$ has undergone phonological change in the Northwestern languages, becoming a glottal /h/ in Tirax. The change from ${ }^{\star} \mathrm{s}$ to /h/ is reported by Brotchie (2009: 713) in other vocabulary items, although it is not systematic in the language, which still retains /s/ as a separate phoneme. Clark (2009: 12-13) observes the change from ${ }^{\star} \mathrm{s}$ to / $\mathrm{h} /$ in other languages of Vanuatu, and it has also been attested in the Polynesian subgroup of the Oceanic language family (see, e.g., Crowley \& Bowern 2010: 89-92). In the second Northwestern language, V'ënen Taut, *s seems to have been replaced with a velar ' $k h$ ' /x/. Clark (2009: 35-36), in his notes on the language, makes no suggestion of a regular sound change from ${ }^{\star} \mathrm{s}$ to $/ \mathrm{x} /$. In the third Northwestern language, Tape, ${ }^{\star} \mathrm{s}$ is retained but there is also a velar segment $/ \mathrm{k} /$ before the vowel. It is perhaps the case that V'ënen Taut and Tape have a modern negator which is the result of the historical ${ }^{\star} \mathrm{sV}$, fused with some other element containing a velar phoneme. The historical *s is apparently lost in V'ënen Taut, but retained in Tape. 
Table 5: Comparing modern preverbal negators.

\begin{tabular}{|c|c|c|c|}
\hline Language & Preverbal morphology & Language & Preverbal morphology \\
\hline Atchin & $s V$ & Nese & (s) be- \\
\hline Aulua & se- & Neve'ei & $s V-$ \\
\hline Avava & sa- & Tape & ska-/ske- \\
\hline Larevet & $s V-$ & Tirax & SUBJ- $h-$ \\
\hline Malua Bay & $p(e / \ddot{e})-$ & Unua & $s e(b(V))$ \\
\hline Maskelynes & $s V-$ & Uripiv & (s)ete \\
\hline Nahavaq & $(s-)$ & V'ënen Taut & $(k h) a-/ a(k h)-$ \\
\hline Naman & $s V-$ & & \\
\hline
\end{tabular}

The phonologically unexpected forms of NEG1 in Malua Bay ( $p(e / \ddot{e})-[\mathrm{p}(\mathrm{e} / ə)-])$ and Nese (be- $\left[{ }^{\mathrm{m}}\right.$ be-]) suggest morphological replacement rather than phonological change. An explanation for this can be derived from Wessels's (2013) synchronic analysis of the Malua Bay language. Wessels (2013: 103-107) identifies preverbal $s(V)$ - as the marker of irrealis mood, which looks very much like negation elsewhere in the languages of Malekula. $P(e / \ddot{e})-$ marks negation as NEG1, in conjunction with NEG2 te. In Malua Bay, pe- or a variant be-can occur on its own in non-negative clauses, indicating a strong desire or intention on the part of the participant coded as grammatical subject (Wessels 2013: 109-111).

Postverbal negators, shown in Table 6, display greater diversity than preverbal negators. This points to the co-opting of negators from a variety of diachronically available sources, and again, this supports Vossen \& van der Auwera's (2014: 62) observation of the tendency for NEG1 to be the older of the two negators.

Historical evidence from Neverver, as well as evidence from languages such as Neve'ei and Naman, suggests that for these languages, the postverbal negator is simply a copy of NEG1. A variety of other sources for NEG 2 can be identified quite easily, and along with NEG1 copying, these can be viewed as emphatic strategies, supporting Vossen \& van der Auwera's claim that emphasis "is a driving force, if not THE driving force, of the Jespersen cycle" (2014: 55). The emphatic te found postverbally in Uripiv is the likely historical source of the -te portion of (s)ete in that language, of postverbal NEG2 te in the language varieties of Malua Bay, Nese, and Atchin, and of the modern standard negator [te] in Tirax. Nahavaq and Larevet may have co-opted a morpheme which routinely collocates with negation, this being the '(not) yet' morpheme, which is attested in Neverver and Avava as $v a$, in Uripiv as wor, and in Neve'ei as vang. Avava's mu NEG2 particle could potentially derive from some kind of politeness device, sourced from a morpheme meaning 'first'. Crowley (2006a: 84-85, 99) made the initial observation that $m u$ is used for these two apparently distinct functions. Van der Auwera 
Table 6: Possible sources of postverbal negators.

\begin{tabular}{|c|c|c|}
\hline Language & Postverbal morphology & Possible source \\
\hline Naman & si & NEG1 (emphatic) doubling \\
\hline Neve'ei & si & \\
\hline Neverver & si & \\
\hline Atchin & te & co-opting and neutralising of \\
\hline Malua Bay & te & emphatic/partitive morpheme \\
\hline Nese & te & \\
\hline Tirax & {$[\mathrm{t} \varepsilon]$} & \\
\hline Unua $^{a}$ & rre & \\
\hline Avava & $m u$ & co-opting of 'first' morpheme \\
\hline Larevet & $\ddot{e} v$ & co-opting of 'yet' morpheme \\
\hline Nahavaq & veq & \\
\hline
\end{tabular}

aUnua's [r] is thought to be a reflex of an older [ $\left.{ }^{n} d\right]$ phoneme (Pearce 2015: 23-24, based on evidence reconstructed in Clark 2009). The partitive source of rre cannot be confirmed absolutely, but it should be noted that the Central Eastern Avava language (Crowley 2006a: 96) and the Central Western Neverver language (Barbour 2012: 220) both have a postverbal partitive morpheme with the shape $\left[{ }^{n} d a\right]$ (see (26)).

(2009: 56, and personal communication therein, from Jack Hoeksema) puts forward the plausible suggestion that the functions are linked, with 'first' bleaching from a more emphatic contribution as in he didn't even know the first thing about checkers, to the present day neutral NEG2. ${ }^{10}$

In spite of there being at least six different standard negation strategies employed in the languages of Malekula, the patterns are consistent with Jespersen Cycles observed elsewhere (van der Auwera 2009, 2010; Vossen \& van der Auwera 2014). Repetition of negative elements, and the co-opting and reanalysis of non-negative elements, including emphatics, are established pathways into double negation.

When looking at the full range of standard negation strategies in the languages included in this study, the synchronic data locates each language within in its own Jespersen Cycle. Overlaying the cycles, we can make sense of the diversity in negation strategies, seeing each language as occupying a stage in a Jespersen macro-cycle, illustrated in Figure 1. Adding the available

10 Another possible source for Avava's mu NEG2 is a continuative morpheme which collocates with negation in other Malekula languages (such as mun in Uripiv, $m u$ in Unua, and mo in Neverver and Neve'ei meaning '(no) longer'). The continuative particle, however, surfaces as min 'imperfective' in Avava (Crowley 2006a: 102) and it is attested as co-occurring with $m u$ NEG2 in a standard negation clause (corpus Crowley/Barbour: ava_11.23). 


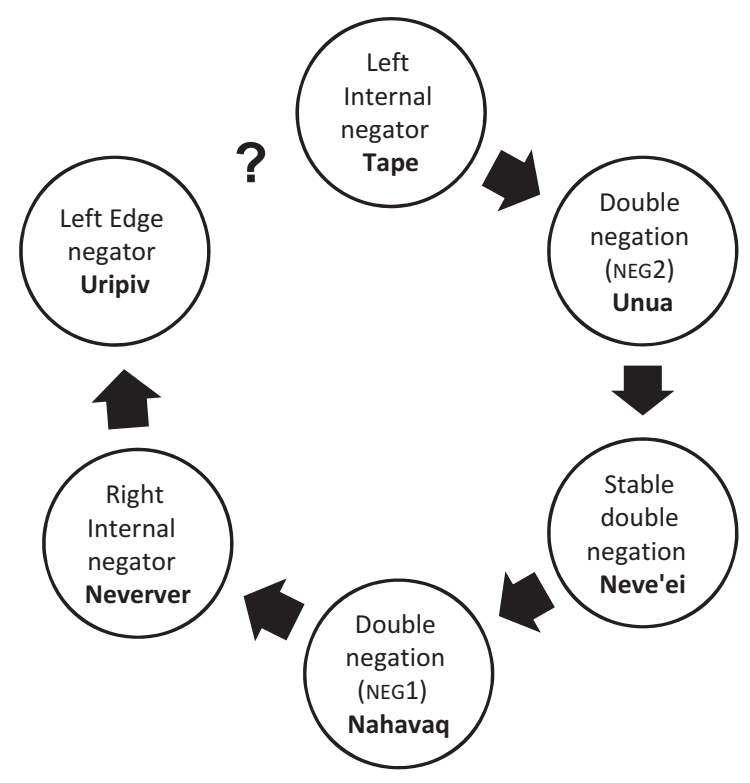

Figure 1: Modelling Malekula negation with a Jespersen macro-cycle.

diachronic data to the synchronic evidence brings the cycle to life, showing how negation is changing through time in the many languages of Malekula.

The Left Edge negation in Uripiv introduces a new structural possibility for how a Malekula language might express standard negation. It is particularly interesting because it does not close the cycle, which would involve the expression of negation in a Left Internal position. Over time Uripiv's negator may well move from the Left Edge into this internal position. It may also co-opt an additional morpheme to produce a new double negation pattern. Both changes will be of considerable interest to observers of the Jespersen Cycles. Further, knowing that the Left Edge is a structural possibility in one language, Malekula researchers may find it employed in other languages, as has been the case in the observed Neverver data.

In sum, combining new field data with older analyses, this study of standard negation in the languages of Malekula has yielded multiple language-specific patterns that can be interpreted as iterations of Jespersen Cycles. These patterns are positionally relevant to the inflected verb, rather than the clause as a larger unit. A close examination of language corpora and associated linguistic commentary reveals language-internal variation motivated by both linguistic and non-linguistic factors. The study reinforces the need for caution in interpreting field data that has not been systematically analysed. It also signals the need for further inquiry into the workings of negation more generally in Malekula 
languages. While beyond the scope of this study, attention to potential asymmetries in negation (see Miestamo 2005) is likely to provide a fruitful line of inquiry for future documentary and descriptive work on Malekula.

Acknowledgements: I gratefully acknowledge the Royal Society of New Zealand's Marsden Fund for grant ll-UOW007 (Exploring Mood in the Oceanic Languages of Vanuatu), as well as support from the University of Waikato's Faculty of Arts and Social Sciences. Thanks also to valuable feedback and comments from two anonymous reviewers.

Abbreviations: $1 / 2 / 3=1 \mathrm{st} / 2 \mathrm{nd} / 3 \mathrm{rd}$ person; $\mathrm{ANA}=$ anaphoric; $\quad$ COMPL $=$ completive; CONT $=$ continuative $; \quad$ DEM = demonstrative; $\quad$ DEM.ANA = anaphoric $\quad$ demonstrative; DEM.ID = identifying demonstrative; DU=dual; DUP=reduplication; $\mathrm{EMPH}=$ emphatic; $\mathrm{INCL}=$ inclusive; $\quad \mathrm{INDF}=$ indefinite; $\quad \mathrm{IRR}=$ irrealis; $\quad \mathrm{NEG}=$ negator; $\quad \mathrm{NSG}=$ non-singular; $\mathrm{NSP}=$ non-specific; $\mathrm{NUM}=$ number; $\mathrm{OBL}=$ oblique; $\mathrm{PART}=$ partitive; $\mathrm{PL}=$ plural; $\mathrm{POSS}=$ possessive; $\mathrm{PST}=$; past tense; $\mathrm{R}=$ realis; $\mathrm{SG}=$ singular; $\mathrm{SUBJ}=$ subject; $\mathrm{TR}=$ transitive.

\section{Appendix A: Standard Malekula Orthography (SMO)}

Malekula languages have traditions of literacy that have developed independently of each other. In some cases, the traditions are strongly tied to missionary work; in other cases, to linguistic or anthropological work. This means that words that sound very similar from one language to the next can have somewhat different spellings. In order to draw out similarities between data from different languages, a Standard Malekula Orthography has been employed.

The Standard Malekula Orthography is a typological convenience. In no way is it intended to supersede existing orthographic practices in individual communities.

Vowels:

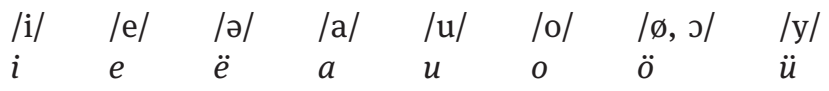

Nasals

$\begin{array}{lllll}/ \mathrm{m} / & / \mathrm{m}^{\mathrm{w}} / & / \mathrm{m} / & / \mathrm{n} / & / \mathrm{n} / \\ m & m w & m^{\prime} & n & n g\end{array}$


Plosives:

$\begin{array}{lllllllllll}/ \mathrm{p} / & / \mathrm{p}^{\mathrm{w}} / & / \mathrm{p} / & /{ }^{\mathrm{m}} \mathrm{b} / & /{ }^{\mathrm{m}} \mathrm{b}^{\mathrm{w}} / & /{ }_{\sim}^{\mathrm{m}} \mathrm{m} / & / \mathrm{t} / & /{ }^{\mathrm{n}} \mathrm{d} / & / \mathrm{k} / & /{ }^{\mathrm{n}} \mathrm{g} / & / \mathrm{P} / \\ p & p w & p^{3} & b & b w & b^{3} & t & d & k & g & q\end{array}$

Fricatives and affricates:

$\begin{array}{llllllll}/ \mathrm{v}, \beta / & / \mathrm{v}^{\mathrm{w}} / & / \mathrm{v}, \boldsymbol{\sim} / & / \mathrm{s} / & / \mathrm{t} / & /{ }^{\mathrm{n}} \mathrm{d} / & / \mathrm{x}, \mathrm{\gamma} / & / \mathrm{h} / \\ v & v w & v^{\prime} & s & c h & j & k h & h\end{array}$

Liquids, Approximants, Trills:

$\begin{array}{lllllll}/ \mathrm{r}, \mathrm{r} / & / \mathrm{r} / & / \mathrm{l} / & / \mathrm{j} / & / \mathrm{w} / & / \mathrm{m}_{\mathrm{B}} / & /{ }^{\mathrm{n}} \mathrm{D} / \\ r & r r & l & y & w & b b & d r\end{array}$

A small number of languages (including Unua) have a phonemic contrast between the flap / $r /$ and the trill / $r$. In these languages, ' $r$ ' is used for the flap, while 'rr' is used for the trill. Strictly speaking, Neve'ei should be written as "Neveqei", using the SMO; however given the orthographic form of the language name in several publications, it is spelt with an apostrophe representing the glottal stop in this work.

\section{Appendix B: Data sources}

Table 7: Case study languages.

\begin{tabular}{|c|c|c|c|c|}
\hline $\begin{array}{l}\text { ISO } \\
\text { code }\end{array}$ & Language & $\begin{array}{l}\text { Alternate } \\
\text { names }\end{array}$ & Published data sources & Corpora \\
\hline lgk & Neverver & $\begin{array}{l}\text { Lingarak, } \\
\text { Bushman's Bay }\end{array}$ & Barbour $(2009,2012)$ & Barbour: nvt \\
\hline vnm & Neve‘ei & Vinmavis & $\begin{array}{l}\text { Crowley (2002), Deacon (1934), } \\
\text { Musgrave }(2001,2007)\end{array}$ & $\begin{array}{l}\text { Crowley/Musgrave/ } \\
\text { Barbour: vnm }\end{array}$ \\
\hline upv & Uripiv & $\begin{array}{l}\text { Northeast } \\
\text { Malekula }\end{array}$ & McKerras (2001) & $\begin{array}{l}\text { McKerras/Barbour: } \\
\text { upv }\end{array}$ \\
\hline sns & Nahavaq & $\begin{array}{l}\text { Sinesip, } \\
\text { Seniang }\end{array}$ & Deacon (1934), Dimock (2009) & Dimock: nhv \\
\hline onu & Unua & $\begin{array}{l}\text { Unua- } \\
\text { Pangkumu, } \\
\text { Rerep }\end{array}$ & Pearce (2015) & \\
\hline mrs & Tape & Maragus & Crowley (2006b) & \\
\hline
\end{tabular}


Table 8: Other Malekula languages discussed.

\begin{tabular}{|c|c|c|c|c|}
\hline $\begin{array}{l}\text { ISO } \\
\text { code }\end{array}$ & Language & Alternate names & Published data sources & Corpora \\
\hline $\mathrm{tmb}$ & Avava & Khatbol, Tisvel & Crowley (2006a) & $\begin{array}{l}\text { Crowley/Barbour: } \\
\text { ava }\end{array}$ \\
\hline $\begin{array}{l}\text { lrv } \\
\text { aul }\end{array}$ & $\begin{array}{l}\text { Larevet } \\
\text { Aulua }\end{array}$ & Larevat & $\begin{array}{l}\text { Paviour-Smith (2005), } \\
\text { Paviour-Smith \& Makenzie } \\
\text { (2005) }\end{array}$ & Barbour: Ivt \\
\hline $\begin{array}{l}\text { klv } \\
\text { (upv) }\end{array}$ & $\begin{array}{l}\text { Maskelynes } \\
\text { Atchin }\end{array}$ & $\begin{array}{l}\text { Kuliviu, Uleveu } \\
\text { (Northeast } \\
\text { Malekula) }\end{array}$ & $\begin{array}{l}\text { Healey (2013) } \\
\text { Capell \& Layard (1980) }\end{array}$ & \\
\hline $\mathrm{nmb}$ & V'ënen Taut & Big Nambas & Fox (1979), Dodd (2013) & Dodd: nmb \\
\hline mll & Malua Bay & Espiegle’s Bay & $\begin{array}{l}\text { Wessels (2013), Holmes } \\
\text { (2014) }\end{array}$ & Wessels: mll \\
\hline$|z|$ & Naman & Litzlitz & Crowley (2006c) & $\begin{array}{l}\text { Crowley/Barbour: } \\
\text { |z| }\end{array}$ \\
\hline- & Nese & Matanvat & Crowley (2006d) & \\
\hline $\mathrm{mme}$ & Tirax & Mae & Brotchie (2009) & \\
\hline
\end{tabular}

\section{References}

Barbour, Julie. 2009. A grammar of the Neverver language of Malakula, Vanuatu. Hamilton, New Zealand: University of Waikato doctoral thesis.

Barbour, Julie. 2011. Contour segments in neverver: Synchronic justifications. Te Reo 54. 3-44. Barbour, Julie. 2012. A grammar of Neverver. Berlin: De Gruyter Mouton.

Brotchie, Amanda. 2009. Tirax grammar and narrative: An Oceanic language spoken on Malakula, north central Vanuatu. Melbourne: University of Melbourne doctoral dissertation. Budd, Peter. 2010. Negation in Bierebo and other languages of Epi, central Vanuatu. Oceanic Linguistics 49. 511-542.

Capell, A. \& John Layard. 1980. Materials in Atchin, Malekula: Grammar, vocabulary and texts (Pacific Linguistics D-20). Canberra: Australian National University.

Charpentier, Jean-Michel. 1979. La langue de Port-Sandwich (Nouvelles-Hébrides): Introduction phonologique et grammaire (Langues et Civilisations à Tradition Orale 34). Paris: Société d'Études Linguistiques et Anthropologiques de France (SELAF).

Clark, Ross. 2009. *Leo Tuai: A comparative lexical study of North and Central Vanuatu languages (Pacific Linguistics 603). Canberra: Australian National University.

Crowley, Terry. 1998. A salvage sketch of Nāti (southwest Malakula, Vanuatu). In Darrell T. Tryon (ed.), Papers in Austronesian linguistics no. 5 (Pacific Linguistics A-92), 101-148. Canberra: Australian National University.

Crowley, Terry. 2002. Vinmavis. In Lynch et al. (eds.) 2002, 638-649. 
Crowley, Terry. 2006a. The Avava language of central Malakula (Vanuatu) (Pacific Linguistics 574). Edited by John Lynch. Canberra: Australian National University.

Crowley, Terry. 2006b. Tape: A declining language of Malakula (Vanuatu) (Pacific Linguistics 575). Edited by John Lynch. Canberra: Australian National University.

Crowley, Terry. 2006c. Naman: A vanishing language of Malakula (Vanuatu) (Pacific Linguistics 576). Edited by John Lynch. Canberra: Australian National University.

Crowley, Terry. 2006d. Nese: A diminishing speech variety of Northwest Malakula (Vanuatu) (Pacific Linguistics 577). Edited by John Lynch. Canberra: Australian National University.

Crowley, Terry \& Claire Bowern. 2010. An introduction to historical linguistics. Oxford: Oxford University Press.

Dahl, Östen. 1979. Typology of sentence negation. Linguistics 17. 79-106.

Dahl, Östen. 2010. Typology of negation. In Horn (ed.) 2010, 9-38.

Deacon, A. Bernard. 1934. Malekula, a vanishing people in the New Hebrides. Edited by Camilla H. Wedgwood. London: Routledge.

Dimock, Laura. 2009. A grammar of Nahavaq (Malakula, Vanuatu). Wellington, New Zealand: Victoria University of Wellington doctoral dissertation.

Dodd, Royce. 2014. V'ënen Taut: Grammatical topics in the Big Nambas language of Malekula. Hamilton, New Zealand: University of Waikato masters thesis.

Dryer, Matthew S. 1988. Universals of negative position. In Michael Hammond, Edith Moravscik, \& Jessica Wirth (eds.), Studies in syntactic typology, 93-124. Amsterdam: Benjamins.

Dryer, Matthew S. 2011a. Negative morphemes. In Matthew S. Dryer \& Martin Haspelmath (eds.) 2011, Chapter 112. http://wals.info/chapter/112 (accessed 16 April 2013)

Dryer, Matthew S. 2011b. Order of negative morpheme and verb. In Dryer \& Martin Haspelmath (eds.) 2011, Chapter 143. http://wals.info/chapter/143 (accessed 21 May 2013).

Dryer, Matthew S. 2011c. Position of negative morpheme with respect to subject, object, and verb. In Matthew S. Dryer \& Martin Haspelmath (eds.) 2011, Chapter 144. http://wals.info/ chapter/144 (accessed 16 April 2013).

Dryer, Matthew S. \& Martin Haspelmath (eds.). 2011. The world atlas of language structures online, 2nd edition. Leipzig: Max-Planck-Institut für evolutionäre Anthropologie. http:// wals.info/

Early, Robert. 1994a. Lewo. In Peter Kahrel \& René van den Berg (eds.), Typological studies in negation, 65-92. Amsterdam: Benjamins.

Early, Robert. 1994b. A grammar of Lewo, Vanuatu. Canberra: Australian National University doctoral dissertation.

Fox, G. J. 1979. Big Nambas grammar (Pacific Linguistics B-60). Canberra: Australian National University.

Gardiner, Alan H. 1904. The word iwn3. Zeitschrift für Ägyptische Sprache und Altertumskunde 41. 130-135.

Healey, David. 2013. A grammar of Maskelynes: The language of Uluveu Island, Vanuatu. Port Vila, Vanuatu: University of the South Pacific doctoral dissertation.

Holmes, Roxanna. 2014. Espiegle's Bay: Grammatical topics. Hamilton, New Zealand: University of Waikato masters thesis.

Horn, Laurence R. 1989. A natural history of negation. Chicago: University of Chicago Press.

Horn, Laurence R. (ed.). 2010. The expression of negation. Berlin: Mouton de Gruyter.

Hovdhaugen, Even \& Ulrike Mosel (eds.). 1999. Negation in Oceanic languages: Typological studies. München: Lincom Europa.

Jespersen, Otto. 1917. Negation in English and other languages. København: Høst. 
Lynch, John. 1998. Pacific languages: An introduction. Honolulu: University of Hawai'i Press. Lynch, John. 2014. Unexpected final vowel retention in Malakula. Open Linguistics 1. 1-16. Lynch, John \& Terry Crowley. 2001. Languages of Vanuatu: A new survey and bibliography (Pacific Linguistics 517). Canberra: Australian National University.

Lynch, John, Malcolm Ross \& Terry Crowley. 2002. The Oceanic languages. Richmond, England: Curzon.

McKerras, Ross. 2001. Uripiv. Unpublished manuscript. Summer Institute of Linguistics, Port Vila, Vanuatu.

Meillet, Antoine. 1912. L'évolution des formes grammaticales. Scientia 12. 384-400. Reprinted in Antoine Meillet, Linguistique historique et linguistique générale, 130-148. Paris: Champion, 1926.

Miestamo, Matti. 2005. Standard negation: The negation of declarative verbal main clauses in a typological perspective. Berlin: Mouton de Gruyter.

Musgrave, Jill. 2001. A grammar of Neve'ei, Vanuatu. Hamilton, New Zealand: University of Waikato master of philosophy thesis.

Musgrave, Jill. 2007. A grammar of Neve'ei, Vanuatu (Pacific Linguistics 587). Canberra: Australian National University.

Paviour-Smith, Martin. 2005. Mood marking on Malakula. Wellington Working Papers in Linguistics 17. 43-58.

Paviour-Smith, Martin \& Willy Makenzie. 2005. Exacting the hen's revenge: An initial enquiry into the nature of narrative in Aulua. Wellington Working Papers in Linguistics 17. 59-73.

Payne, John R. 1985. Negation. In Timothy Shopen (ed.), Language typology and syntactic description, Vol. 1: Clause structure, 197-242. Cambridge: Cambridge University Press.

Pearce, Elizabeth. 2015. A grammar of Unua. Berlin: De Gruyter Mouton.

Ray, Sidney Herbert. 1926. A comparative study of the Melanesian Island languages. Cambridge: Cambridge University Press.

Ross, Malcolm, Andrew Pawley \& Meredith Osmond. 2011. Introduction. In Malcolm Ross, Andrew Pawley \& Meredith Osmond, The lexicon of Proto Oceanic: The culture and environment of ancestral Oceanic society, Vol. 4: Animals (Pacific Linguistics 621), 1-16. Canberra: Australian National University.

van der Auwera, Johan. 2009. The Jespersen Cycles. In Elly van Gelderen (ed.), Cyclical change, 35-71. Amsterdam: Benjamins.

van der Auwera, Johan. 2010. On the diachrony of negation. In Horn (ed.) 2010, 73-109.

Vanuatu National Statistics Office. 2009. 2009 National population and housing census: Basic tables report Volume I. Port Vila: Vanuatu National Statistics Office.

Vossen, Frens \& Johan van der Auwera. 2014. The Jespersen cycles seen from Austronesian. In Maj-Britt Mosegaard Hansen \& Jacqueline Visconti (eds.), The diachrony of negation, 47-82. Amsterdam: Benjamins.

Wessels, Kanauhea. 2013. Malua Bay: A description of the Malua Bay language (Malekula, Vanuatu). Hamilton, New Zealand: University of Waikato masters thesis.

Whaley, Lindsay J. 1997. Introduction to typology: The unity and diversity of languages. Thousand Oaks, CA: Sage. 
Copyright of Linguistic Typology is the property of De Gruyter and its content may not be copied or emailed to multiple sites or posted to a listserv without the copyright holder's express written permission. However, users may print, download, or email articles for individual use. 